\title{
Financial and credit support of the competitiveness the enterprises of the sphere of tourism in the conditions of promoting it in the world market
}

\author{
Khusanova D.Sh. ${ }^{1}$ \\ ${ }^{1}$ Department of Finance, Tashkent Institute of Finance, Tashkent, Uzbekistan \\ Email: dilorom.xusanova@rambler.ru
}

\begin{abstract}
The article is devoted to the characterization of the priority direction of development of financial and credit support to the subjects of the tourism sector, namely, its implementation through the assessment of the competitiveness of the tourism product. It was noted that the competitiveness of the tourism product is closely tied to a specific market and the requirements of strictly defined groups of consumers, and therefore should be assessed by meeting the requirements of consumers.
\end{abstract}

Keywords: tourism enterprises, tourism products, competitiveness of tourism product, financial and credit support for tourism

\section{INTRODUCTION}

Determination of the priority direction of development of financial and credit support to the subjects of the tourism industry is currently a crucial task. The proposed directions for further reforming the financial and credit support of tourism entities are aimed at the development of a competitive domestic tourism sector, corresponding to the level of countries with developed market economies.

The economic, political and investment attractiveness of Uzbekistan ensures a stable and dynamic development of tourism. In the Strategy of social and economic development of Uzbekistan for 2017-2021, tourism is recognized as one of the priority sectors of the economy. According to statistical analysis in 2017, the main indicators of the tourism industry have increased. In comparison with the last year, the volume of outbound tourism increased by $12.9 \%$, domestic tourism increased by $10.3 \%$ and amounted to 5.8 million people, the total number of subjects of the tourist industry increased by $14 \%$. Currently, hundreds of tourist organizations with foreign partners in more than 90 countries of the world work in Uzbekistan. The vast majority of tourist companies in Uzbekistan provide services for receiving, sending tourists and domestic tourism.

The priority direction of the development of tourism is financial and credit support for the tourist product, increasing the competitiveness of its product.

To date, the subject of research at all stages of the development of a market economy is the problem of competition and competitiveness. When studying the genesis of competition, its driving forces, it can be concluded that the concept of competition is multivalued and not covered by any one definition. Its nature and form are different in different markets and in different market situations.

Of course, the approach to determining competitiveness as a complex of consumer properties of a tourism product, regardless of its value, is the most common. It is assumed that low competitiveness leads to lower prices and vice versa. In this case, the price is identified with the quality of tourist products, although quality is only one of the factors of competitiveness.

In the economic literature there are attempts to approach the definition of the competitiveness of a tourism product through price as a universal characteristic, which reflects all consumer and exchange properties of the tourism product. For the development of such properties of competing tourism products should be manifested in the difference in prices, which constitute the competitiveness of these tourism products.

The number of possible factors in the current situation can be attributed to the outpacing growth of tourist products. However, in order to achieve growth of tourist products and, accordingly, 
"competitiveness", it is necessary to take into account that it must be considered from the point of view of the consumer [1]. It follows that when choosing a tourist product, the consumer should focus only on those features that are of significant interest to him. These parameters, which reflect the usefulness of the tourist product, is the most important condition for choosing a tourist product. This process can mean the coincidence of its properties with the characteristics of the predicted demand.

In an effort to acquire the tourism product that best meets the needs (that means it has the highest consumer effect), the consumer can not ignore the costs that will be associated with these tourism products. Of course, he seeks to achieve the optimal ratio of the properties of this tourist product and his expenses, that is, to get the maximum effect per unit of costs. Therefore, to determine competitiveness, it is essential not only to compare tourist products according to the degree of compliance with a particular need, to take into account consumer costs associated with these products, but also to provide financial and credit support to tourism products in terms of promoting it on the world market. It should be taken into account that the purchase of a tourist product means not only a prerequisite, the starting point for satisfying a need, but also all parties to financial and credit support for competitiveness - financial and credit support largely depends on the state of a tourist enterprise. The total costs, taking into account such support, consist of two parts: one-time (price of the tourist product) and current (costs at the place of stay - excursions, additional food, clothing, car rental, entertainment, expansion of the activities of tourist enterprises, etc.). In general, the total amount of these costs acts for the consumer as the price to meet the need (price of consumption).

In our opinion, these features of the definition of competitiveness should be given more careful attention, since they are one of the most problematic at the present stage, and require a clearly defined conceptual approach to their decision.

Hence, we can conclude that competitiveness is a complex multidimensional characteristic of a tourist product, which determines its preference in both domestic and foreign market compared to similar competing products, both in terms of the degree of compliance with the needs and financial expenses of tourists to meet them, provides the opportunity to realize the tourism product at a certain point in time in a particular market [1].

The definitions quoted, in fact, are certainly true, but clearly insufficient for any serious solution to the problems of the effective development of a competitive tourism product. In particular, in order to optimize financial inflows and outflows, it is necessary not only to improve the investment climate in them, but also to actively promote the formation of a competitive territorial tourism enterprise, a relatively independent, focused on the specific needs of a given territory, tourist services and investment resources.

The most significant is the implementation of the state (local) investment policy, which, as practice has shown, can be carried out by organizations with the participation of territorial authorities, or so-called territorial investment banks in support of tourist entities. Currently, a specialized bank designed to credit only tourist entities is absent and this extremely complicates the process of relations and interaction between banks and tourist entities. The main purpose of creating a specialized bank for servicing tourist entities is the transition to a comprehensive financial and credit service for tourists and tourist entities. The need to create this kind of specialized bank was particularly acute after the adoption of the concept of reforming tourism.

The actual evaluation by tourist-consumers of competitiveness is made in the process of buying and selling a tourist product. However, in the process of financial and credit support, it is equally important to determine methods for assessing its potential, calculated competitiveness. Nowadays, the identification of potential competitiveness is the basis for developing new tourist products, substantiating decisions about the need to modify existing ones, and form and implement pricing policies in the context of financial and credit support.

\section{LITERATURE ANALYSIS}

In addition, in the scientific literature, the methodology for assessing the potential competitiveness of a tourist product is not sufficiently developed. All available techniques are based on an assessment of the competitiveness of the tourism product in general. Consider an integral method for assessing the competitiveness of a product as applied to a tourist product, which, with some differences in methodology, is proposed by such economists as A.P. Durovich [1], E.P. Golubkov [3], R. A. Fathutdinov, M. Porter[ 2].

At this stage of economic reform, in order to substantiate the list of indicators required for evaluation, it is important to take into account that the competitiveness of a tourist product is closely tied 
to a specific market and the requirements of strictly certain groups of consumers. Therefore, they are caused only by those indicators that are of considerable interest to the consumer. Indicators of tourism products that go beyond the specified limits should not be considered in evaluating competitiveness as having no relation to it.

In this regard, I would like to share our vision of some possible ways to solve these problems.

\section{RESEARCH METHODOLOGY}

In turn, the most significant problem today is due to the identification of indicators of competitiveness. It is enough to recall that the indicators of competitiveness of the tourism product are divided into classification and evaluation. The first ones express the belonging to a certain type of services, define a group of consumers and are used at the initial stages of the assessment of competitiveness to form a group of analogues of the estimated tourism product.

Estimated indicators of the tourist product on the role of assessing competitiveness can be divided into groups:

-regulated (i.e., used to verify compliance with the mandatory requirements that must be met by the tourist product);

- comparative (i.e., used to compare products competing in the tourist market by the degree of customer satisfaction with certain characteristics).

\section{ANALYZES AND RESULTS}

In the assessement of competitiveness, special attention should be paid to regulated indicators, which create the possibility of realizing a tourist product. Mandatory requirements for all types of tourist services are: the safety of life and health, the safety of property of tourists and sightseers, as well as environmental protection. If these requirements are not met or do not meet regulatory requirements, then a further assessment of competitiveness would be inappropriate.

Accounting for regulated indicators is methodically provided by the introduction of an index that takes only two values: 0 or 1 . If the tourism product meets the standards, then the index is 1 , if it does not, it is 0 . The group index for the entire set of regulated indicators is defined as the product of single indicators for each of them:

$$
G_{r} I N D_{r i}=R I_{i=1}^{n} s i_{r i ~}
$$

$G_{r} I N D_{r i}{ }^{-}$group index for regulated indicators $S i_{r i i^{-}}$single indicator (si) for the $\mathrm{i}$ - th regulated indicator, $\mathrm{n}$ - number of regulated indicators to be assessed.

Comparable indicators include: integrity, targeting, utility, flexibility, reliability [3].

The first indicator means - the completeness of the product and its ability to meet the specific needs of tourists.

The second means - the focus of the tourist product on a specific segment of consumers.

The third means the ability of a tourism product to serve one or more travel goals.

The fourth indicator means the ability of the tourism product and service system to adapt to the individual needs of the consumer and to be immune to the replacement of personnel serving the tourists.

The fifth indicator means - compliance with the contents of the tourist product and advertising, the ability of the enterprise to provide the tourist product in accordance with the terms of the contract [3].

In modern conditions, the peculiarity of tourism is the conditions affecting the evaluation of the tourist product by the consumer. First of all, this is a subjectivity determined by the emotional state of the client, i.e. tourist. The assessment is formed under the action of the so-called "humanitarian technologies", which are formed on the basis of comparable indicators determining the process of providing tourist services in the context of response, competence, and material environment.

Here the first characterizes the desire and desire of staff to help tourists, i.e. consumers in solving their problems, taking into account the prevailing conditions and desires.

The second determines to what extent the staff has the skills and knowledge necessary for the qualified provision of services.

The third characterizes the tangible component of services [2].

At the same time, the list of indicators determining competitiveness, although relatively stable, but their significance varies depending on the conditions prevailing in the tourist product market, therefore, a hierarchy of indicators is established. Weighting coefficients, which should be equal to 1 in the amount, are 
calculated by an expert method, taking into account information obtained from studying consumer behavior.

Annals of tourist products included in a group of tourist products should be characterized by the same values of qualification indices and belonging to the same market segment, the basic tourist product is selected from the group of analogues for comparison (a competing tourist product that is consistently sold on a specific market in large volumes).

As a rule, significant indicators that determine the competitiveness of a tourism product do not have a natural physical measure, but are characterized by qualitative descriptions. Therefore, comparative indicators based on expert assessments are expressed by conditional quantitative estimates - points.

Next, a sequential comparison of individual comparative indicators of competitiveness of the estimated and basic tourist products is carried out. In this case, the values of individual indicators of competitiveness are estimated by the formula (2).

$$
V A_{i c}=\frac{V \mathrm{CO}_{\text {ietp }}}{V_{\text {i btp }}}
$$

Where:

$\mathrm{VA}_{\mathrm{ic}}$ - the value of the assessment of the $\mathrm{i}$-th comparative index of competitiveness; $\mathrm{VCO}_{\mathrm{i} \text { etp }}$ - the value of the $\mathrm{i}$-th comparative index of the estimated tourism product (tp); $\mathrm{V}_{\mathrm{i} \text { btp }}$ - the value of the $\mathrm{i}$-th indicator of the basic tourist product.

It should be borne in mind that to obtain on the basis of a single group index, it is necessary to combine them taking into account the significance of each individual comparative indicator:

$$
G_{r} I N D_{c i}=\sum_{i=1}^{n} V A_{i c i} \operatorname{Coef}_{\cdot w i}
$$

where:

$\mathrm{G}_{\mathrm{r}} \mathrm{IND}_{\mathrm{ci}}$ - group index of competitiveness by comparable indicators; $\mathrm{VA}_{\mathrm{i} \text { ci }}$ - the value of the assessment of the $\mathrm{i}$-th comparative indicator; Coef. w $_{\mathrm{i}}$ is the weight coefficient of the i-th comparative competitiveness indicator; $\mathrm{n}$ is the number of single comparative indicators taken in the evaluation.

At the same time, in order to find a group index of competitiveness by economic indicators $\left(\mathrm{G}_{\mathrm{r}} \mathrm{IND} \mathrm{D}_{\mathrm{ei}}\right)$, it is necessary to compare the consumption prices of the estimated tourism product with the consumption price of the base tourism product $\left(\mathrm{P}_{\mathrm{cbtp}}\right)$ :

$$
G_{r} I N D_{e i}=\frac{P_{c e t p}}{P_{c b t p}}
$$

where:

$\mathrm{G}_{\mathrm{r}} \mathrm{IND}_{\mathrm{ei}}$ - group index of competitiveness by economic indicators; $\mathrm{P}_{\text {cetp }}$ - the price of consumption of the estimated tourism product; $\mathrm{P}_{\text {cbtp }}$ - the price of consumption of the basic tourist product.

At the same time, the complex indicator of the estimated tourism product $\left(\mathrm{C}_{\mathrm{om} . \mathrm{i}}\right)$ is calculated on the basis of group indices by comparable indicators $\left(\mathrm{G}_{\mathrm{r}} \mathrm{IND}_{\mathrm{ci}}\right)$ and economic indicators $\left(\mathrm{G}_{\mathrm{r}} \mathrm{IND}_{\mathrm{ei}}\right)$ (formula $5)$ :

$$
\mathrm{Com}_{\cdot i}=\frac{G_{r} I N D_{c i}}{G_{r} I N D_{e i}}
$$

Here, using formula 5, it will be possible to reveal differences in the consumer effect attributable to the purchase and consumption of the compared tourist products.

At the same time, if $\mathrm{C}_{\text {om. }}<1$, then the estimated tourist product is inferior in competitiveness to the base one, if $\mathrm{C}_{\text {om.p }}>1$, then the estimated tourist product exceeds it. With equal competitiveness $\mathrm{C}_{\text {om.p }}=1$.

In the context of the formed conclusion, the policy regarding the estimated tourism product is determined. In case of a positive outcome of the assessment, a decision is made to introduce the tourist product on the market, but with direct financial and credit support. For taking into account tax and credit benefits, with a negative assessment, it is necessary to develop measures to increase the competitiveness of the tourist product with the subsequent submission of proposals to expand tax breaks and lower the bank interest rate. 
The results of the assessment of the competitiveness of the tourism product also serve to determine the optimal approach to the reception of foreign and local tourists, followed by the elaboration of a special policy aimed at developing the tourism industry, increasing the number of foreign tourists and foreign exchange earnings.

The results of the assessment of the competitiveness of the tourism product also serve to determine the optimal approach to the reception of foreign and local tourists, followed by the elaboration of a special policy aimed at developing the tourism industry, increasing the number of foreign tourists and foreign exchange earnings.

Investments in tourism can be carried out by both private and public sectors of the economy or international financial institutions.

State investments are possible to form and strengthen the material and technical base of tourism enterprises, to provide tax incentives to tourism enterprises in order to positively influence the country's tourist image. Among the main types of financial and credit mechanisms of influence on the development of tourism are:

1. Loans at interest rates beneficial to borrowers. At the same time, the state will have to compensate for the difference between the financed interest rate and the market one. This becomes more important in conditions when the refinancing rate of the Central Bank is unstable and has a movement in the direction of growth, as evidenced by the figures in fig. 1 data (see: Fig. 1).

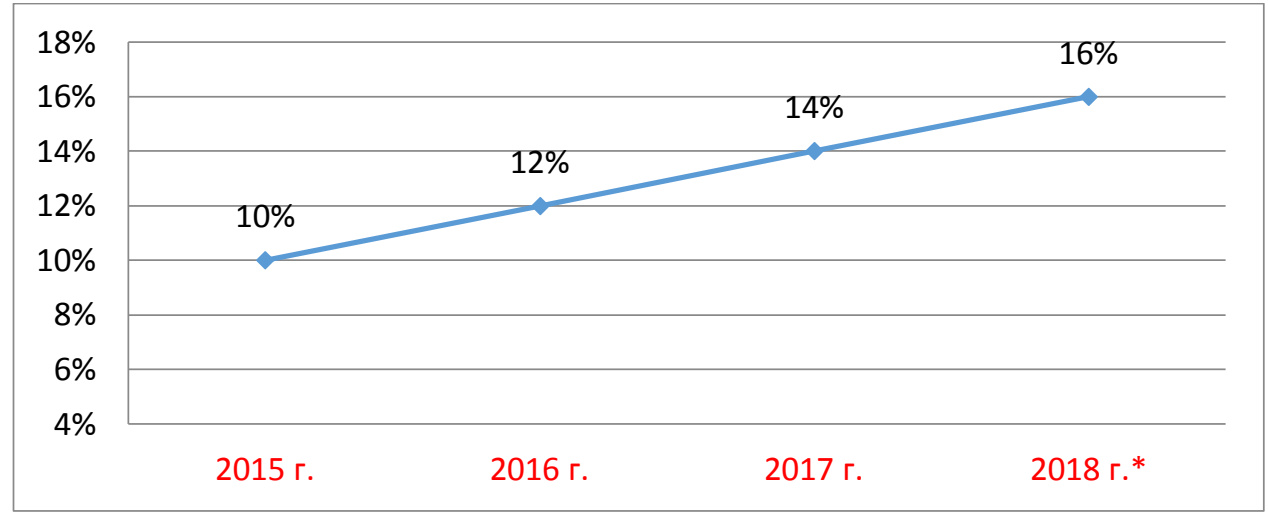

Fig. 1. Changes in the refinancing rate of the Central Bank for 2015 -2018 (* from September 25, 2018)

As follows from Figure 1 in recent years, the Central Bank has changed the refinancing rate in the direction of growth. This should place new credit conditions for innovatively developing service enterprises, in particular, for tourism. For the negative impact of interest rates on the activities of tourist products can lead to higher prices and lower inflows of foreign tourists.

2. Sale or lease of land. This is an important factor that can influence the development of the tourist product. But in recent years, this mechanism does not give a tangible result due to the increase in the land tax rate or the sale of land for the construction of a tourist facility. And this is a very risky event.

3. Tax privileges, protection from double taxation with the help of ratios with other countries, reduction of duties, direct subsidies, provision of guarantees for investments for the purpose of attracting foreign investors, etc.

\section{CONCLUSIONS AND SUGGESTIONS}

Investing in tourism, taking into account the application of the above financial and credit mechanisms, is a risky undertaking, since this type of activity is very sensitive to both external and internal factors (i.e., economic, political, climatic, legal and other changes) to narrow down subjects capable of receiving the flow of tourists and thereby significantly affect the flow of monetary resources from tourist services.

Investing in tourism, taking into account the application of the above financial and credit mechanisms, is a risky undertaking, since this type of activity is very sensitive to both external and internal factors (i.e., economic, political, climatic, legal and other changes) to narrow down subjects capable of 
receiving the flow of tourists and thereby significantly affect the flow of monetary resources from tourist services.

The development of a healthy specific environment through the strengthening of tourist potential, of course, can provide tourism for developing countries, in particular, Uzbekistan, in the future, to advance to world markets.

\section{REFERENCES}

1. Durovich A.P. /Marketing research in tourism: Tutorial. - Publisher: Peter, 2008. - p.384.

2. Competitive Strategy: A Methodology for Analyzing Industries and Competitors /Michael E. Porter; translation from English. - M.: Alpina Business Books, 2005. - p.454

3. Golubkov E.P. Marketing research, theory, methodology and practice. Textbook. - 3rd ed., M. Publisher "Fin-press", 2003. -p. 496. 